TITLE:

\title{
Silicon dioxide thin films prepared by chemical vapor deposition from tetrakis (dimethylamino)silane and ozone
}

\author{
$\operatorname{AUTHOR}(S)$ :
}

MARUYAMA, T; SHIRAI, T

\section{CITATION:}

MARUYAMA, T ... [et al]. Silicon dioxide thin films prepared by chemical vapor deposition from tetrakis (dimethylamino)silane and ozone. APPLIED PHYSICS LETTERS 1993, 63(5): 611-613

\section{ISSUE DATE:}

1993-08-02

URL:

http://hdl.handle.net/2433/43525

\section{RIGHT:}

Copyright 1993 American Institute of Physics. This article may be downloaded for personal use only. Any other use requires prior permission of the author and the American Institute of Physics. 


\title{
Silicon dioxide thin films prepared by chemical vapor deposition from tetrakis (dimethylamino)silane and ozone
}

\author{
Toshiro Maruyama and Toshimasa Shirai \\ Department of Chemical Engineering, Faculty of Engineering, Kyoto University, Kyoto 606, Japan
}

(Received 14 December 1992; accepted for publication 18 May 1993)

\begin{abstract}
Silicon dioxide thin films were prepared by a low-temperature atmospheric-pressure chemical vapor deposition method. The raw materials were tetrakis (dimethylamino) silane and ozone in oxygen gas. At a substrate temperature above $40^{\circ} \mathrm{C}$, the thin films were obtained with a high deposition rate.
\end{abstract}

Silicon dioxide $\left(\mathrm{SiO}_{2}\right)$ thin films are widely used in the semiconductor industry for passivation and masking layers. High-quality $\mathrm{SiO}_{2}$ layers have been traditionally prepared by the thermal oxidation of silicon. An alternative is to deposit $\mathrm{SiO}_{2}$ by chemical vapor deposition (CVD) methods. $^{1,2}$ Various CVD methods have been proposed; for example, silane-based CVD, and tetraethoxysilane (TEOS)-based CVD. Recently, the CVD method using TEOS and ozone has attracted much attention because of the possibility of lowering the process temperature. ${ }^{3,4}$

In this letter, tetrakis(dimethylamino)silane ( $\left.\mathrm{Si}\left[\mathrm{N}\left(\mathrm{CH}_{3}\right)_{2}\right]_{4}\right)$ and ozone in oxygen gas are proposed as source materials for obtaining $\mathrm{SiO}_{2}$ films by the CVD method. The deposition conditions, the structure, and hardness of the deposited film will be described in comparison with those for the CVD without mixing ozone and for TEOS/ozone CVD.

Figure 1 shows the schematics of the experimental apparatus and reactors. Tetrakis (dimethylamino) silane (Shin-Etsu Chemical Co., Ltd.) was used as the silicon source. It is a liquid at room temperature. It was heated at a temperature of $40^{\circ} \mathrm{C}$, and the vapor was carried into the reactor with nitrogen gas as a carrier. The flow rate of the carrier gas was $300 \mathrm{~cm}^{3} / \mathrm{min}$. The ozone was generated in an ozonator, which converts a fraction of the incoming oxygen gas. The flow rate of oxygen gas was $100 \mathrm{~cm}^{3} / \mathrm{min}$. A $6 \mathrm{~W}$ low-pressure mercury lamp (wavelength $184.9 \mathrm{~nm}$ )

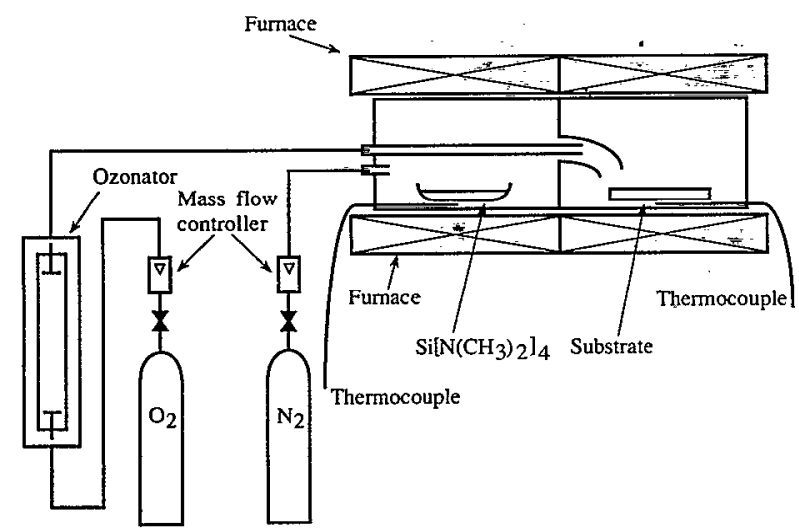

FIG. 1. Schematic representations of experimental equipment and reactors. was used as the ozonator. The ozone and oxygen gas were mixed with the vapor of silicon source in the entrance nozzle. Depositions were made at atmospheric pressure. For the CVD without mixing ozone, only oxygen gas was mixed in the same flow condition as that with mixing ozone. For comparison, the TEOS/ozone CVD was made under the same deposition conditions of this study. (The $\mathrm{SiO}_{2}$ films could be obtained at substrate temperatures above $200^{\circ} \mathrm{C}$.)

Borosilicate glass plates and silicon (100) singlecrystal wafers were used as substrates. In the reactor, the substrate was set horizontally.

The infrared spectra were obtained by means of a Fourier transform infrared spectrometer (Shimadzu FTIR4300 ). The samples were prepared by depositing films on silicon single-crystal substrates. The dynamic hardness of the film was measured with an ultramicrodynamic hardness meter (Shimadzu DUH-200). The etch rate was obtaincd by dipping the film into the $P$-etching solutions, which consisted of $\mathrm{HF}, \mathrm{HNO}_{3}$, and $\mathrm{H}_{2} \mathrm{O}\left(\mathrm{HF}: \mathrm{HNO}_{3}: \mathrm{H}_{2} \mathrm{O}\right.$ $=3: 2: 69$ in weight). Ozone concentration was measured by means of a multipurpose recording spectrophotometer. The absorbance at $253.7 \mathrm{~nm}$ showed that the ozone concentration for oxygen gas flow rate of $100 \mathrm{~cm}^{3} / \mathrm{min}$ was $463 \mathrm{ppm}$.

In the CVD with mixing ozone, transparent $\mathrm{SiO}_{2}$ films were obtained at substrate temperatures above $40^{\circ} \mathrm{C}$. The lower limit of the substrate temperature is much lower than that for the CVD without mixing ozone, where the

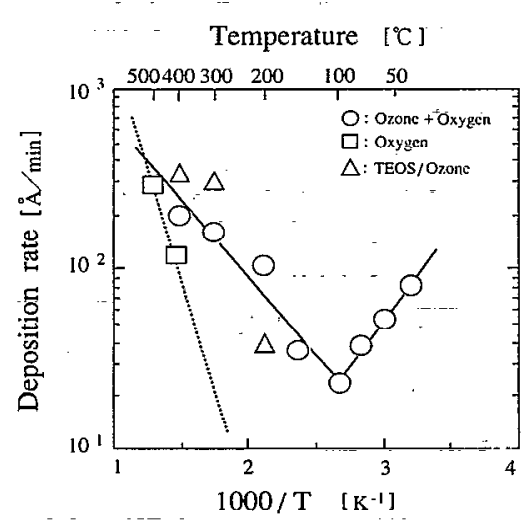

FIG. 2. Arrhenius plots of deposition rates. 

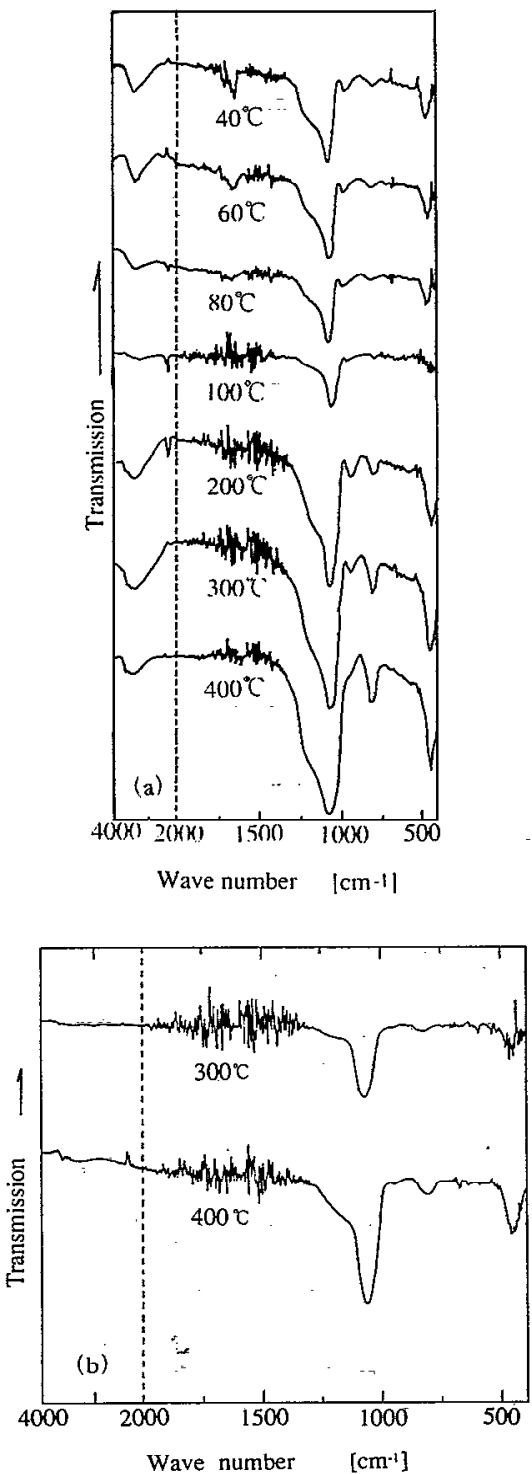

$\mathrm{SiO}_{2}$ films could be grown at a temperature above $300^{\circ} \mathrm{C}$. The films prepared by the CVDs with and without mixing ozone showed smooth surface morphologies, and the particle generations were very low.

Figure 2 shows the Arrhenius plots of deposition rates. The deposition rate for CVD with mixing ozone is higher than that for the CVD without mixing ozone. For the CVD with mixing ozone, however, the deposition rate decreases with increasing substrate temperature in a temperature range $40-100^{\circ} \mathrm{C}$. This is probably because the adsorption of tetrakis (dimethylamino) silane on the substrate is dominating.

Figures 3(a)-3(c) show infrared absorption spectra of films deposited at some different substrate temperatures. Concerning the results for CVD with mixing ozone [Fig. 3(a)] and for TEOS/ozone CVD [Fig. 3(c)], the spectra are similar to each other; i.e., absorption peaks at about 1080,800 , and $460 \mathrm{~cm}^{-1}$ represent Si-O-Si asymmetricbond-stretching vibration, network Si-O-Si symmetricbond-stretching vibration and network Si-O-Si bondbending vibration. A trace of the $\mathrm{Si}-\mathrm{OH}$ bond (absorption peaks at about 950 and $3300 \mathrm{~cm}^{-1}$ ) can be

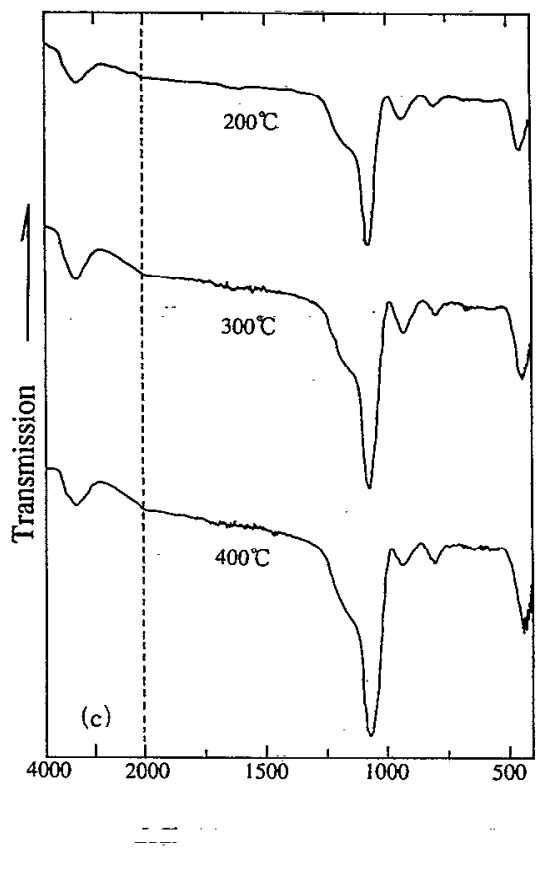

FIG. 3. IR transmission spectra of (a) $\mathrm{SiO}_{2}$ films prepared by CVD with mixing ozone, (b) $\mathrm{SiO}_{2}$ films prepared by CVD without mixing ozone, and (c) $\mathrm{SiO}_{2}$ films prepared by TEOS/ozone CVD.

identified. Concerning the results for CVD without mixing ozone [Fig. 3(b)], however, the Si-OH peak remains essentially nonexistent.

Figure 4 shows the dynamic hardness of the film as a function of substrate temperature. It is nearly independent of the substrate temperature at a temperature above $200^{\circ} \mathrm{C}$, being consistent with the results of infrared absorp-

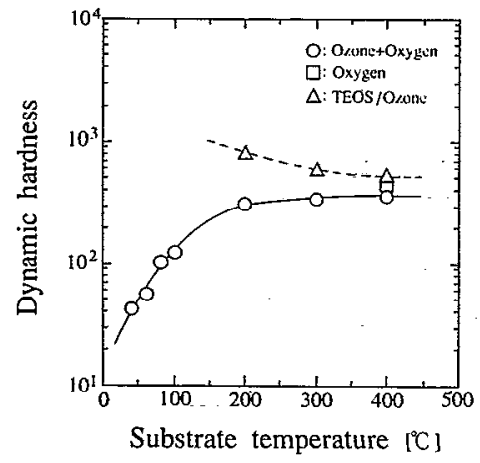

FIG. 4. Dynamic hardness of $\mathrm{SiO}_{2}$ film. 


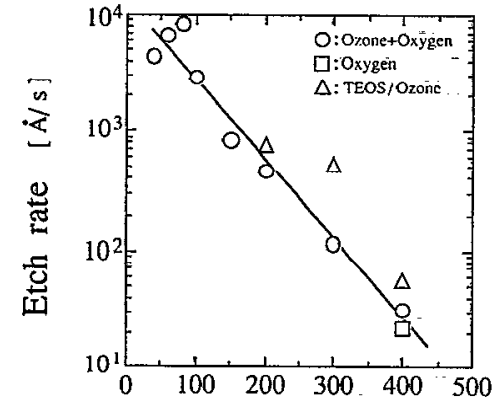

Substrate temperature $\left[{ }^{\circ} \mathrm{C}\right]$ the etch rate decreases exponentially. At a substrate temperature above $200^{\circ} \mathrm{C}$ it is nearly equal to the corresponding value for TEOS/ozone CVD. Being consistent with the results of the dynamic hardness, the films prepared at temperatures below $100^{\circ} \mathrm{C}$ prove to be of poorer quality.

In conclusion, silicon dioxide thin films were prepared by a low-temperature atmospheric-pressure chemical vapor deposition method. The raw materials were tetrakis(dimethylamino)silane and ozone in oxygen gas. At a substrate temperature above $40^{\circ} \mathrm{C}$, the thin films were obtained with a high deposition rate.

${ }^{1}$ T. Maruyama and J. Shionoya, Jpn. J. Appl. Phys. 28, L2253 (1989)

${ }^{2}$ T. Maruyama and T. Tago, Thin Solid Films (to be published).

${ }^{3}$ Y. Ikeda, Y. Numasawa, and M. Sakamoto, NEC Res. Develop. 94, 1 (1989).

${ }^{4}$ K. Kotani, M. Matsuura, A. Fujii, H. Genjou, and S. Nagao, IEDM Tech. Dig. 669 (1989). 